\title{
DEGRADAÇÃO DE DOXICICLINA PELO PROCESSO OXIDATIVO DE FENTON
}

\author{
A. A. BORGHI, M. S. A. PALMA \\ Universidade de São Paulo, Departamento de Tecnologia Bioquímico-Farmacêutica \\ E-mail para contato: msapalma@usp.br
}

\begin{abstract}
RESUMO - A Doxiciclina é um antibiótico da família das Tetraciclinas, de amplo espectro, presente em efluentes industriais, domésticos e provenientes de áreas rurais. Seu principal inconveniente no meio ambiente é a potencialização do surgimento de bactérias resistentes a ele. Os experimentos foram realizados conforme um planejamento experimental tipo DCCR, sendo estudadas as influências da temperatura $\left(T=0\right.$ a $\left.40^{\circ} \mathrm{C}\right)$, concentração inicial de $\mathrm{H}_{2} \mathrm{O}_{2}\left(C_{\mathrm{H} 2 \mathrm{O} 2}=100\right.$ a $\left.900 \mathrm{ppm}\right)$ e de $\mathrm{Fe}^{2+}\left(C_{\mathrm{Fe} 2+}=5\right.$ a $\left.120 \mathrm{ppm}\right)$ sobre a concentração residual final de Doxiciclina e Carbono Orgânico Total. Para a análise da concentração do fármaco residual foi utilizado o método espectrofotométrico. As concentrações residuais de Doxiciclina variaram de 0,0 a 55,8 ppm. O processo é incapaz de reduzir o TOC além de $30 \%$, desta forma deixando no efluente moléculas orgânicas, as quais se mostraram não tóxicas através de testes de citotoxicidade com Escherichia coli. A melhor condição operacional foi $T=35,0^{\circ} \mathrm{C}, C_{H 2 O 2}=611 \mathrm{ppm}$ e $C_{\mathrm{Fe} 2+}=25 \mathrm{ppm}$. O processo é pouco influenciado pela temperatura, razoavelmente influenciado pela concentração de ion ferroso e bastante influenciado pela concentração de peróxido de hidrogênio.
\end{abstract}

\section{INTRODUÇÃO}

A principal via de entrada de fármacos no meio ambiente é através do esgoto doméstico, tratados ou não. No entanto, também se deve considerar os efluentes das indústrias farmacêuticas e químicofarmacêuticos, descarte inadequado de medicamentos vencidos, efluentes das zonas rurais e a presença de antibióticos no estrume animal utilizado para fertilização do solo (Aga, 2008). O consumo mundial de antibióticos aumentou drasticamente na última década e desta forma cresceu também a sua excreção na sua forma original e de seus metabólitos. A maior parte dos antibióticos ingeridos não são totalmente metabolizados por seres humanos e animais e assim cerca de 25 a $75 \%$ dos antibióticos pode deixar o organismo em sua forma inalterada (Khan e Ongerth, 2004; Watkinson et al., 2009; Rivas et al., 2011). A Doxiciclina pertence à família das tetraciclinas e são o segundo grupo de antibióticos mais produzidos e consumidos em todo o mundo ( $\mathrm{Gu}$ e Karthikeyan, 2005; Borghi e Palma, 2014). As tetraciclinas são consideradas antibióticos seguros e tem muitas propriedades favoráveis, tais como o amplo espectro de atividade, baixa toxicidade, baixo custo, e pode, na maioria dos casos, ser administrado por via oral (Jeong et al., 2010). Os efeitos colaterais mais comuns são náuseas, vômitos e diarréia. A única restrição ao seu uso é por mulheres grávidas e crianças durante o crescimento devido a sua deposição nos ossos e calcificação de dentes. Os efeitos menos comuns são 
fotossensibilidade induzida, urticária, dor de cabeça, dor abdominal, hipertensão, febre, leve leucopenia, anemia e trombocitopenia. Pacientes que tomam insulina devem ter acompanhamento especial, uma vez que as tetraciclinas podem aumentar a persistência de insulina no organismo e, por isto, exigem maior acompanhamento (Zhanel et al., 2004). Além da utilização em seres humanos, as tetraciclinas são usadas na terapia animal para tratar infecções e promover o crescimento. Oxitetraciclina e clorotetraciclina são dois dos dez antimicrobianos autorizados nos Estados Unidos como promotores de crescimento para bovinos (Jeong et al., 2010). As tetraciclinas são o terceiro antibiótico mais consumido, depois da penicilina e quinolonas e devido ao seu uso indiscriminado tem sido detectado um número crescente de bactérias resistentes às tetraciclinas (Pereira-Maia et al., 2010). O fenômeno da resistência bacteriana é na verdade hoje em dia uma grande preocupação, pois há cepas resistentes a quase todos os antibióticos atualmente conhecidos (Rocha et al., 2011). O presente trabalho tem como objetivo estudar a degradação da Doxiciclina pelo processo Fenton e otimizar as condições experimentais (temperatura, concentração inicial de peróxido de hidrogênio e concentração inicial de ion ferroso) para se obter a menor concentração residual final de Doxiciclina e de Carbono Orgânico Total (TOC). Também são apresentados os resultados de citotoxicidade dos resíduos. Este trabalho dá continuidade ao trabalho já publicado de Borghi et al., (2012).

\section{MATERIAIS E MÉTODOS}

\subsection{Equipamento}

A aparelhagem experimental utilizada nos ensaios consistiu de banho termostatizado, refrigerador, béqueres, balões volumétricos, balança semi-analítica, filtros, agitadores mecânicos, termopares, pHmetro, buretas e espectrofotômetro.

O esquema do equipamento utilizado está mostrado na Figura 1.

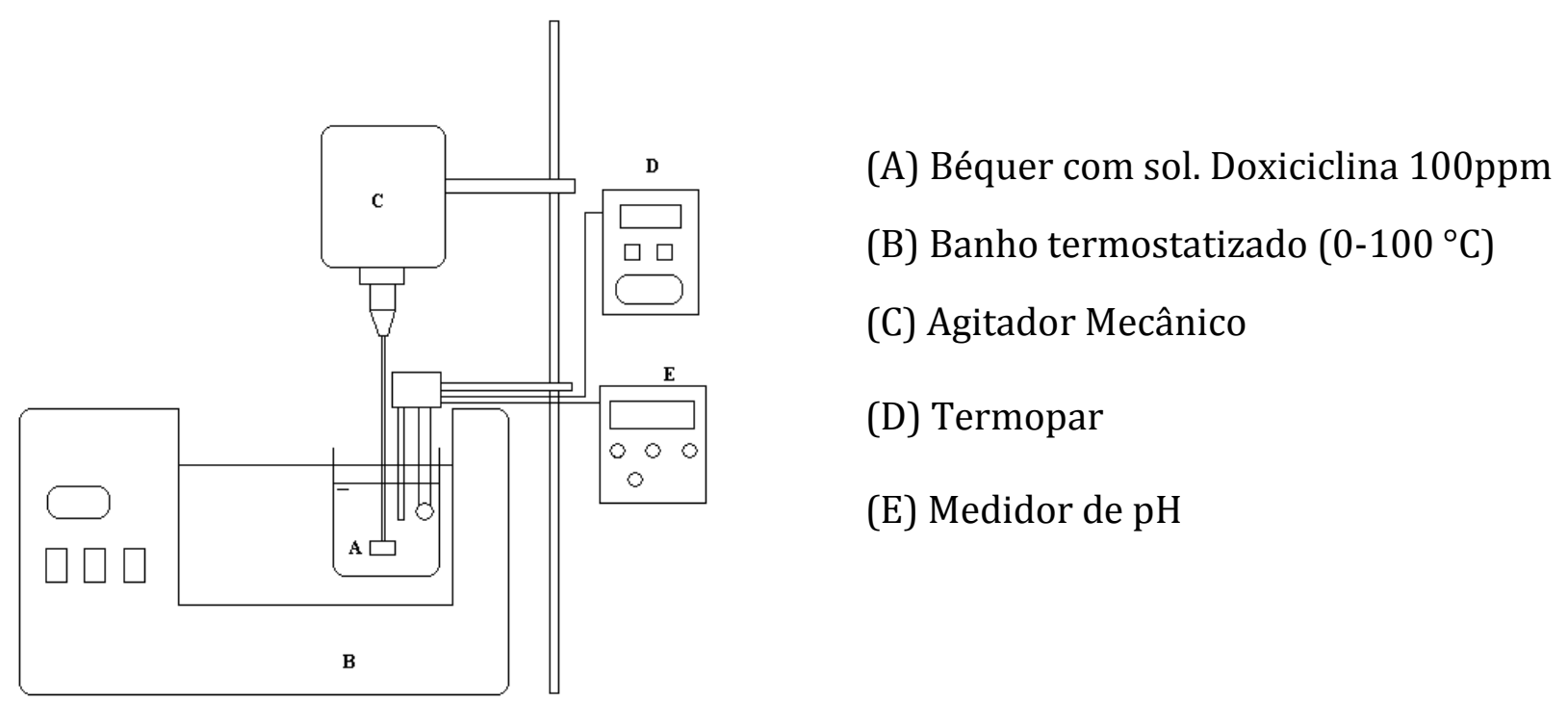

Figura 1 - Equipamento experimental para os ensaios de oxidação por Processo Fenton. 
O béquer (A) contendo a solução aquosa de hiclato de doxiciclina $100 \mathrm{mg} / \mathrm{L}$ ficava imerso em um banho termostatizado (B) com temperatura ajustável entre 0 e $100^{\circ} \mathrm{C}$. O béquer dispunha de um agitador mecânico (C), um termopar (D), um medidor de $\mathrm{pH}$ (E). Nas dosagens e amostragens utilizaram-se micropipetas de 0 a 20, 20 a 200 e de 100 a $1000 \mu \mathrm{L}$.

\subsection{Planejamento Experimental}

Os ensaios de oxidação da Doxiciclina foram realizados de acordo com planejamento experimental do tipo Delineamento Composto Central Rotacional, DCCR (Barros Neto et al., 2002; Rodrigues e Iemma, 2005).

Os valores das variáveis estudadas estão discriminados na Tabela 1. O planejamento completo foi apresentado anteriormente (Borghi et al., 2012).

Tabela 1 - Variáveis estudadas codificadas

\begin{tabular}{|c|c|c|c|c|c|}
\hline Variáveis & $\mathbf{- 1 , 6 8}$ & $\mathbf{- 1}$ & $\mathbf{0}$ & $\mathbf{+ 1}$ & $\mathbf{+ 1 , 6 8}$ \\
\hline $\mathbf{C}_{\mathbf{F e}}^{+2}(\mathbf{p p m}), \mathbf{X}_{\mathbf{1}}$ & 5 & 28,3 & 62,5 & 96,7 & 120 \\
\hline $\mathbf{C}_{\mathbf{H 2 O 2}}(\mathbf{p p m}), \mathbf{X}_{\mathbf{2}}$ & 100 & 262 & 500 & 738 & 900 \\
\hline $\mathbf{T}\left({ }^{\circ} \mathbf{C}\right), \mathbf{X}_{\mathbf{3}}$ & 0,0 & 8,0 & 20,0 & 32,0 & 40,0 \\
\hline
\end{tabular}

\subsection{Ensaio}

Transferia-se $200 \mathrm{~mL}$ de solução de Doxiciclina 100 ppm para béquer coberto e envolto com papel alumínio, protegido da luz ambiente, colocava-se este béquer em banho termostatizado na temperatura estabelecida no planejamento experimental $\left(0,8,0,20,0,32,0 \mathrm{ou} 40,0{ }^{\circ} \mathrm{C}\right)$ sob agitação com agitador mecânico, quando atingida a temperatura desejada dentro do béquer, adicionava-se a este a solução de Sulfato Ferroso de modo que a concentração de $\mathrm{Fe}^{2+}$ no meio tivesse o valor desejado (5, 28,3, 62,5, 96,7 ou 120 ppm) e um volume de Peróxido de Hidrogênio necessário para que a concentração no meio tivesse o valor desejado (100, 262, 500, 738 ou 900 ppm).

O ensaio era iniciado com a adição do peróxido de hidrogênio, quando então o cronômetro era disparado e coletavam-se alíquotas em tempos pré-determinados.

\subsection{Análises Químicas}

Determinação espectrofotométrica da concentração de Doxiciclina: Os íons de ferro podem interferir na análise, sendo necessária a sua remoção do meio. Outro interferente nesta análise é o peróxido de hidrogênio que reage com o íon molibdato formando um complexo amarelo, resultando em um falso incremento nos resultados. Nesta quantificação foi necessário o uso de uma solução inibidora do sistema Fenton proposto por Mota et. al. (2005). Esta solução era composta de iodeto de potássio, sulfito de sódio e hidróxido de sódio em meio aquoso. 


\section{9 a 22 de outubro de 2014 \\ Florianópolis/SC}

Coletava-se em frasco contendo $1 \mathrm{~mL}$ da solução inibidora do sistema Fenton, $1 \mathrm{~mL}$ de alíquota do meio reacional. Homogeneizava-se e filtrava-se com filtro de $0,45 \mu \mathrm{m}$ acoplado a seringa, coletando o filtrado em frasco de vidro.

Transferia-se $1 \mathrm{~mL}$ do filtrado para balão volumétrico de $5 \mathrm{~mL}$ e adicionava-se a este $1 \mathrm{~mL}$ de solução $\mathrm{Na}_{2} \mathrm{MoO}_{4} 5 \times 10^{-3} \mathrm{M}, 0,5 \mathrm{~mL}$ de $\mathrm{NaNO}_{3} 1 \mathrm{M}$ e $0,5 \mathrm{~mL}$ de solução tampão acetato $0,01 \mathrm{M}, \mathrm{pH}$ 5,0. Avolumava-se o balão com água destilada e homogeneizava-se.

Transferia-se para uma cubeta de vidro de $1 \mathrm{~cm}$ e efetuava-se a leitura em espectrofotômetro em comprimento de onda de $390 \mathrm{~nm}$. Paralelamente eram preparadas soluções de calibração para determinação da concentração de Doxiciclina por comparação.

Carbono orgânico total: Para adequação da amostra, adicionava-se 3,5 mL de solução inibidora do sistema Fenton a $3,5 \mathrm{~mL}$ do meio reacional. Esta mistura era filtrada com filtro de acetato de celulose $0,45 \mu \mathrm{m}$ diretamente para um vial e a este se adicionava 5 gotas de $\mathrm{H}_{2} \mathrm{SO}_{4} 1: 5$, garantindo $\mathrm{pH}$ na faixa entre 2,0 e 3,0. Com auxilio de filme plástico, a abertura do vial era selada, possibilitando a homogeneização e posterior determinação no equipamento COT-5000A (Shimadzu), localizado no Centro de Sistemas de Engenharia Química - CESQ do Departamento de Engenharia Química da Escola Politécnica da USP.

\section{RESULTADOS E DISCUSSÃO}

\subsection{Oxidação de doxicilina}

Os resultados dos ensaios segundo o planejamento DCCR já foram publicados anteriormente (Borghi et al., 2012) e não serão mostrados aqui. Observou-se uma grande variação nos resultados de $C_{\text {Doxi,Residual }}$ que variaram de 0 a $55,8 \mathrm{mg} / \mathrm{L}$. Casualmente os menores valores, 0 a $2 \mathrm{ppm}$, que foram obtidos para o ponto central $\left(T=20{ }^{\circ} \mathrm{C}, \mathrm{C}_{\mathrm{H} 2 \mathrm{O} 2}=500 \mathrm{ppm} \mathrm{e} \mathrm{C}_{\mathrm{Fe}}{ }^{2+}=62,5 \mathrm{ppm}\right)$. Estes resultados também mostraram que o planejamento utilizado contemplou condições operacionais que influenciaram significativamente a variável dependente.

Os resultados foram tratados com o Software Statistica ${ }^{\circledR}$ e mostraram que apenas a concentração de peróxido de hidrogênio (variável codificada $\left.\mathrm{X}_{2}\right)(\mathrm{p}<0,05)$. Os valores finais de TOC não foram influenciados significativamente por $T, \mathrm{C}_{\mathrm{H} 2 \mathrm{O} 2} \mathrm{e}_{\mathrm{Fe}}{ }^{2+}$, e apresentaram uma queda máxima de $30 \%$.

De acordo com Pandey et al. (2000), a melhor condição operacional também pode ser estimada através da aplicação das derivadas parciais da equação da superfície, gerada pelo software Statistica ${ }^{\circledR}$, em relação a $X_{1}, X_{2}$ e $X_{3}$ e que, quando igualadas a zero, fornecem o mínimo da função.

Através da resolução do sistema de equações algébricas lineares obtidas determinou-se a melhor condição operacional para se obter a concentração residual mínima de Doxiciclina, resultando em $C_{F e}{ }^{2+}=25 \mathrm{ppm}, C_{\mathrm{H} 2 \mathrm{O} 2}=611 \mathrm{ppm}$ e $T=35^{\circ} \mathrm{C}$. Esta condição operacional foi admitida como o ponto de partida para se efetuar um estudo paramétrico das variáveis, cujas condições experimentais e resultados estão mostradas nas Figuras 2 a 4. 

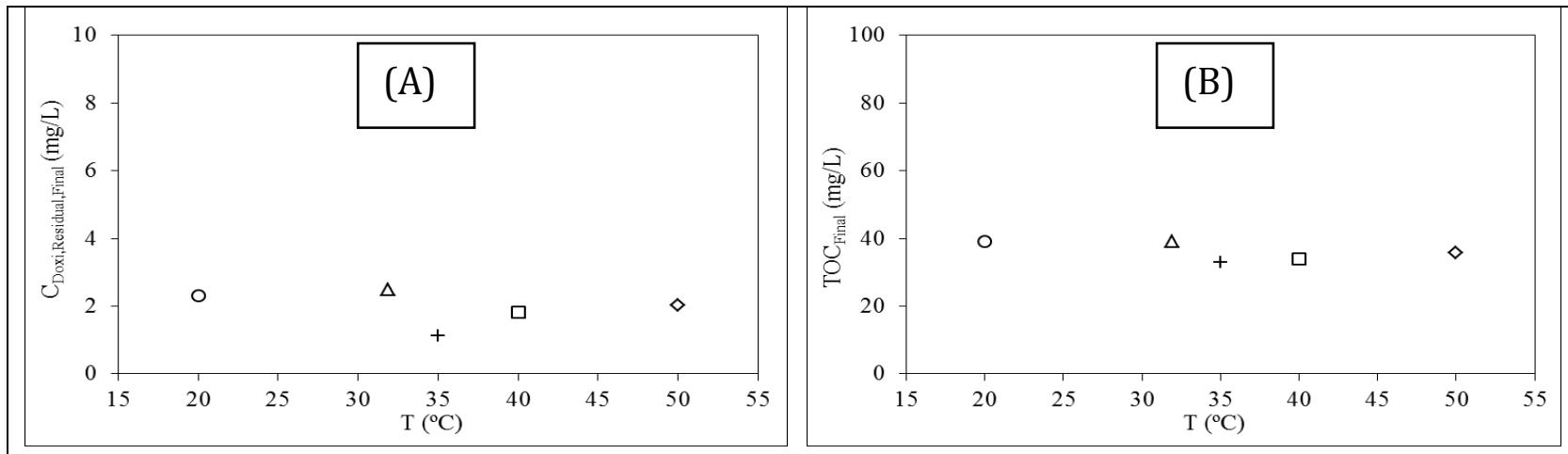

Figura 2 - Influência da temperatura sobre (A) $\mathrm{C}_{\text {Doxi.Residual.Final }} \mathrm{e}$ (B) TOC $_{\text {Final }}$
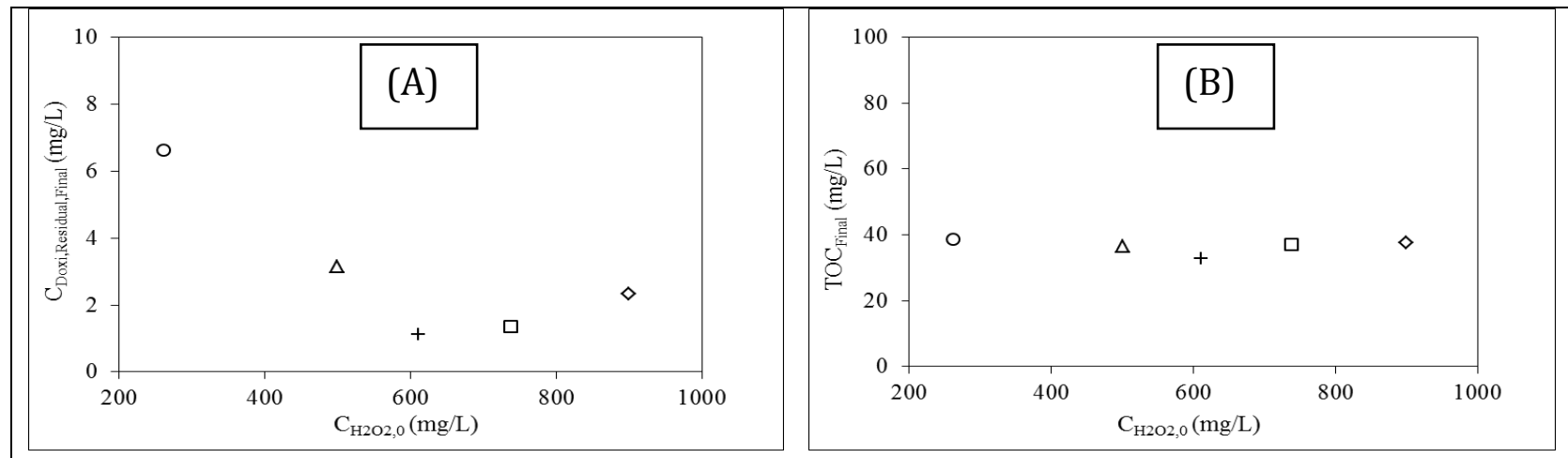

Figura 3 - Influência da concentração inicial de peróxido de hidrogênio sobre (A) $\mathrm{C}_{\text {Doxi.Residual.Final }} \mathrm{e}(\mathrm{B}) \mathrm{TOC}_{\text {Final }}$
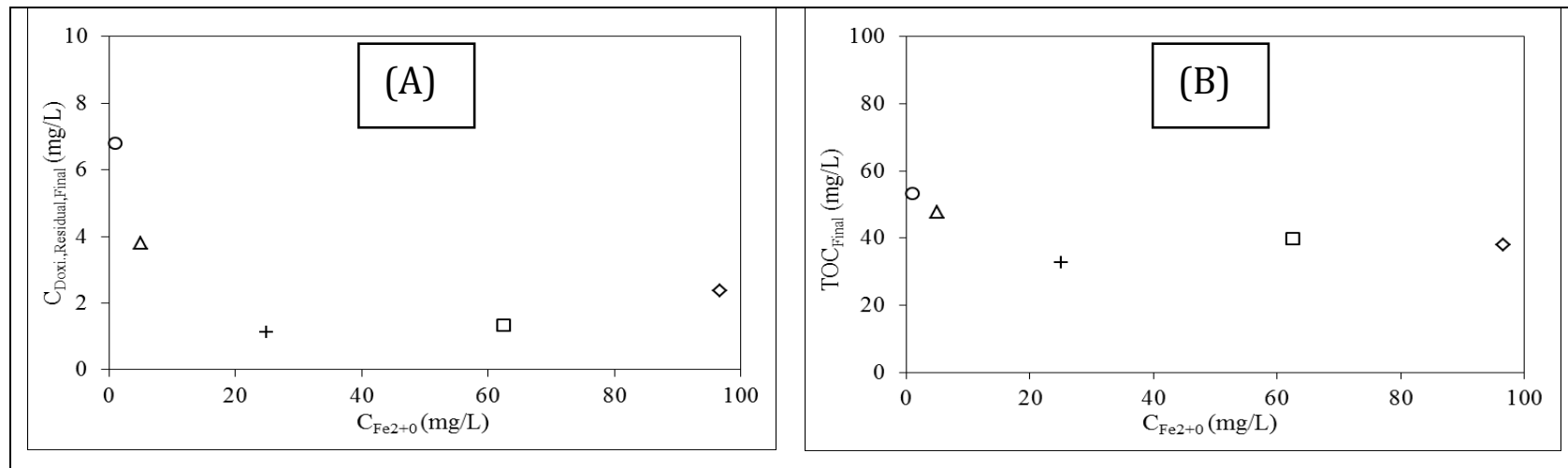

Figura 4 - Influência da concentração inicial de ion ferroso sobre (A) $C_{\text {Doxi.Residual.Final }}$ (B) TOC $_{\text {Final }}$

A Figura 2 confirma os resultados da análise de variância, ou seja, A temperatura não influencia o processo em termos de $\mathrm{C}_{\text {Doxi,Residual,Final }}$ e de TOC. Acreditamos que a concentração 


\section{9 a 22 de outubro de 2014 \\ Florianópolis/SC}

residual final de Doxiciclina tenha sido completamente oxidada a compostos que tinham a mesma reação com molibdato, desta forma, mascarando a análise espectrofotmétrica. Algumas análises em HPLC-MS mostraram que a Doxiciclina desaparece em tempos de reação inferiores a 10 min. Os produtos de degradação originados durante o processo sofrem ataque do radical hidroxila, originando moléculas instáveis, que são capazes de reagir com outras moléculas presentes no meio, possibilitando a formação de moléculas mais estáveis, mantendo uma concentração elevada de COT do meio reacional.

A Figura 3A mostra que a resposta do processo para $\mathrm{C}_{\text {Doxi,Residual,Final }}$ são bastante influenciados pela concentração inicial de peróxido de hidrogênio. Para baixas concentrações de peróxido é possível que não haja formação de radicais hidroxila em concentração suficiente para degradar a Doxiciclina e demais subprodutos orgânicos. Como esperado, a TOC (Figura 3B) é independente da concentração de peróxido, porque detecta compostos orgânicos, inclusive a Doxiciclina, que pode estar presente no final do ensaio.

A Figura 4A mostra que a Doxiciclina, e demais compostos com a mesma reposta espectrofotométrica, são bastante influenciados para baixas concentrações de ion ferroso $\left(\mathrm{C}_{\mathrm{Fe}}{ }^{2+}\right.$ inferiores a $20 \mathrm{ppm}$ ) e independentes para $\mathrm{C}_{\mathrm{Fe}}{ }^{2+}$ superiores a $20 \mathrm{ppm}$. O mesmo comportamento é observado para o TOC. Para concentrações de ion ferroso é possível que não haja formação de radicais hidroxila em concentração suficiente para degradar a Doxiciclina e demais subprodutos orgânicos.

\subsection{Avaliação da Concentração Inibitória Mínima dos Resíduos}

Os ensaios de concentração inibitória mínima são importantes para se determinar qual a menor concentração que um determinado agente antibiótico deve ter para exercer ação inibitória sobre um determinado microrganismo. A Concentração Inibitória Mínima (CIM) da Escherichia coli ATCC 25922 à Doxicilina é de 1,0 a 4,0 $\mu \mathrm{g} / \mathrm{mL}$ (FDA, 2013).

Os ensaios para a determinação da CIM foram realizados em triplicata utilizando-se como organismo de controle a Escherichia coli. A concentração inibitória mínima da Doxiciclina foi de 1,6 $\mu \mathrm{g} / \mathrm{ml}$, compatível com a descrita na literatura (FDA, 2013) para Escherichia coli. O antibiótico oxidado não foi capaz de inibir o crescimento em concentração menor ou igual a $25 \%$ da solução inicial, equivalente a $25 \mu \mathrm{g} / \mathrm{mL}$ de Doxiciclina oxidada. A concentração do tratamento não foi aumentada acima de $25 \%$ para não diluir o meio de cultura em excesso, o que interfere na cinética de crescimento bacteriano. Através deste teste é possível afirmar que o efluente foi tóxico para o microrganismo estudado, pois não inibiu seu crescimento celular. A ausência de inibição também evidencia que a amostra mais concentrada contém menos que $6,4 \mu \mathrm{g} / \mathrm{ml}$ do antibiótico (quatro vezes o valor do CIM, pois estava diluído a 25\%), ou seja, houve inativação de no mínimo 94\% da quantidade inicial de Doxiciclina.

\subsection{Avaliação da Citotoxicidade do Resíduo da Degradação da Doxiciclina}




\section{9 a 22 de outubro de 2014 \\ Florianópolis/SC}

Os ensaios de citotoxicidade foram realizados com o efluente na concentração real do experimento e concentrado 10 vezes em evaporador rotativo a vácuo, sendo a citotoxicidade medida pelo teste do MTT.

Os resultados obtidos mostraram que 20 a $30 \%$ de amostra pode afetar o crescimento celular, mesmo que a amostra seja o tampão fosfato (solução salina) não prejudicial à célula, não há diferença significativa entre o efluente e o branco da reação, o que mostra que não houve geração de subprodutos tóxicos a esse tipo celular no processo de tratamento do efluente. Comparando-se os dados da Doxiciclina esta manteve-se tóxica à célula em altas concentrações, sendo seu efeito, portanto, dependente da dose.

$\mathrm{Na}$ tentativa de avaliar a influência do efluente e branco da reação, estes foram concentrados 10 vezes. Observou-se que não havia diferença significativa entre o efluente e o branco da reação concentrados, pois a concentração do efluente e branco da reação aumentou a viabilidade celular, confirmando que a citotoxicidade anterior era relacionada à diluição do meio de cultura, e não a toxicidade do tratamento, não apresentando toxicidade significativa às células L929 em até 50\% de concentração (5\% de solução 10 vezes concentrada), que foi a maior concentração testada.

\section{CONCLUSÕES}

A análise paramétrica mostrou que as 3 variáveis estudadas $\left(\mathrm{C}_{\mathrm{H} 2 \mathrm{O} 2}, \mathrm{C}_{\mathrm{Fe}}{ }^{2+} \mathrm{e} \mathrm{T}\right)$ exercem efeito na concentração residual final de Doxicilina, porém, com base na análise de resíduos do software Statistica ${ }^{\circledR}$, as variáveis que mais influenciaram o processo foram a concentração inicial de peróxido de hidrogênio e de ion ferroso, respectivamente. A melhor condição experimental determinada pelo planejamento fatorial foi $\mathrm{C}_{\mathrm{Fe}}{ }^{2+}=25 \mathrm{mg} / \mathrm{L}, \mathrm{C}_{\mathrm{H} 2 \mathrm{O} 2}=611 \mathrm{mg} / \mathrm{L} \mathrm{e} \mathrm{T}=35^{\circ} \mathrm{C}$. Para estas condições obtevese a menor concentração residual final de cloridrato de Doxiciclina e de TOC, que foram de 1,1 e 32,8 mg/L, respectivamente. Os resultados de Carbono Orgânico Total mostraram que a carga orgânica não foi reduzida, formando-se moléculas não detectáveis pelo método espectrofotométrico, que era específico para a determinação do fármaco.

A avaliação da citotoxicidade e da Concentração Inibitória Mínima (CIM) dos resíduos pela Escherichia coli mostraram que a Doxiciclina teve suas características antibióticas neutralizadas, sendo assim factível tecnologicamente o tratamento de resíduos contendo Doxicilina pelo processo Fenton nas condições determinadas segundo o planejamento fatorial DCCR. Na continuidade deste trabalho foram determinados em HPLC-MS os produtos de degradação da Doxicilina e numa publicação posterior mostraremos aqueles novos resultados e faremos uma discussão sobre suas toxicidades.

\section{REFERÊNCIAS}

AGA, D. S. Fate of Pharmaceuticals in the environment and in water treatment systems. Boca Raton: CRC Press, 2008.

BARROS NETO, B.; SCARMINIO, I. S.; BRUNS, R. E. Como fazer experimentos, Pesquisa e desevolvimento na ciência e na indústria. 2a. Ed.Campinas: Editora UNICAMP, 2002. 


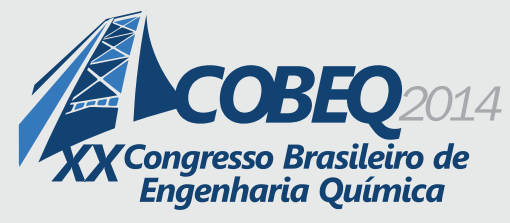

19 a 22 de outubro de 2014
Florianópolis/SC

BORGHI, A.A.; NAKAGAWA, M.I.;PALMA, M.S.A.; - "Oxidação química de hiclato de doxiciclina pelo processo Fenton: condição ótima de operação de acordo com o planejamento fatorial DCCR". In: XIX Congresso Brasileiro de Engenharia Química. Búzios, RJ, 9 a 12 de setembro de 2012.

BORGHI. A. A.; PALMA, M. S. A. Tetracycline: production, waste treatment and environmental impact assessment. Braz. J. Pharm. Sci., v. 50, n. 1, p. 1-16, 2014.

FDA. U.S. Food and Drug Administration. Doryx (doxycycline hyclate) Capsule, Delayed Release

Pellets. Disponível em: http://www.accessdata.fda.gov/drugsatfda_docs/label/2008/050582s027lbl.pdf. Acesso em: 04 junho 2013.

GU, G.; KARTHIKEYAN, K.G. Interaction of tetracycline with aluminum and iron hydrous oxides? Environ. Sci. Technol., v. 39, p. 2660-2667, 2005.

JEONG, J.; SONG, W.; COOPER, W.J.; JUNG, J.; GREAVES, J. Degradation of tetracycline antibiotics: Mechanisms and kinetic studies for advanced oxidation/reduction processes. Chemosphere, v.78, p.533-540, 2010.

KHAN, S.J.; ONGERTH, J.E. Modelling of pharmaceutical residues in Australian sewage by quantities of use and fugacity calculations. Chemosphere, v. 54, p. 355-367, 2004.

MOTA, A. L. N.; MURANAKA, C. T.; MORAES, J. E. F.; NASCIMENTO, C. A. O.; CHIAVONEFILHO, O. Aplicação do processo Foto-Fenton na fotodegradação do fenol em meio aquoso utilizando lâmpadas de luz negra como fonte de radiação. XXI Congreso Interamericano de Ingeniería QuímicaPeru, 2005.

PANDEY, P. K.; RAMASWAMY, H. S. GELASIS, D. Water-holding capacity and gel strength of rennet curd as affected by high-pressure treatment of milk. Food Research Intern., v. 33, p. 655-663, 2000.

PEREIRA-MAIA, E.C.; SILVA, P.P.; ALMEIDA, W.B.; SANTOS, H.F.; MARCIAL, B.L.; RUGGIERO, R.; GUERRA, W. Tetraciclinas e glicilciclinas: uma visão geral. Quím. Nova, v. 33, p. 700-706, 2010.

RIVAS, J.; ENCINAS, A.; BELTRAN, F.; GRAHAN, N. Application of advanced oxidation processes to doxycycline and norfloxacin removal from water. J. Environ. Sci. and Health, Part A, v. 46, p. 944-951, 2011.

ROCHA, D.P.; PINTO, G.F.; RUGGIERO, R.; OLIVEIRA, C.A.; GUERRA, W.; FONTES, A.P.S.; TAVARES, T.T.; MARZANO, I.M.; PEREIRA-MAIA, E.C. Coordenação de metais a antibióticos como uma estratégia de combate à resistência bacteriana. Quím. Nova, v. 34, p. 111-118, 2011.

RODRIGUES, M. I.; IEMMA, A. F. Planejamento de experimentos e otimização de processos: uma estratégia sequencial de planejamentos. Campinas: Editora Casa do Pão Editora, 2005.

WATKINSON, A.J.; MURBYD, E.J.; KOLPINE, D.W.; COSTANZO, S.D. The occurrence of antibiotics in an urban watershed: From wastewater to drinking water. Sci. Tot. Environ., v. 407, p. 2711-2723, 2009.

ZHANEL, G.G.; HOMENUIK, K.; NICHOL, K.; NOREDDIN, A.; VERCAIGNE, L.; EMBIL, J.; GIN, A.; KARLOWSKY, J.A.; HOBAN, D.J. The glycylcyclines: a comparative review with the tetracyclines. Drugs, v. 64, p. 63-88, 2004. 